\title{
Response of Sandy Soil Stabilized by Polymer Additives
}

\author{
Chao Xing ${ }^{1}$, Xueyan Liu ${ }^{2 *}$ and Kumar Anupam ${ }^{2}$ \\ ${ }^{1}$ School of Transportation Science and Engineering, Harbin Institute of Technology, Heilongjiang, China \\ ${ }^{2}$ Section of Pavement Engineering, Faculty of Civil Engineering \& Geosciences, Delft University of Technology, The Netherlands
}

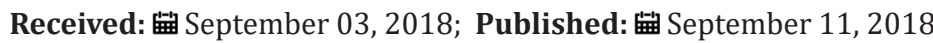

*Corresponding author: Xueyan Liu, Section of Pavement Engineering, Faculty of Civil Engineering \& Geosciences, Delft University of Technology, The Netherlands

\begin{abstract}
Traditional sandy soil stabilizers such as lime cement, fly ash and bituminous materials, etc., usually require long curing time. Hence now a day, polymer stabilizer is used more extensively because of its stable chemical property and shorter curing time. For the developing organization, it is important to judge the performance of stabilized soil during its developing stages only. This paper aims to highlight a quick and easy test to evaluate the mechanical performance of such polymer based stabilized soil. For this study, three different kinds of polymer stabilizers at developing stage were evaluated against a market ready product. The analysis of the test result include a comparison of the strength, moisture loss rate and strain energy under different curing time, polymer type, polymer additive amount and test conditions. This study shows that the strength of the stabilized sandy soil is significantly increased both under wet and dry conditions by using the polymer additives. With the procedure mentioned in the paper it was easier to identify the relative merits and demerits of each product.
\end{abstract}

Keywords: Polymer Stabilizer; Sandy Soil; Unconfined Compressive Test; Permeability Test

\section{Introduction}

In the desert areas, large amount of soil is lifted by wind, the road is covered by the soil as shown in Figure 1, therefore, soil stabilization is important for road capacity. Soil stabilization is the alteration of one or more soil properties, by mechanical or chemical means, in order to maximize the suitability of soil for a given construction purpose by improving in-situ soil properties. Soils may be stabilized to increase engineering properties like strength and durability; or to diminish erosion and dust generation. The stabilized product should not only enhance desired soil properties, but they should also create a soil material/soil system which can sustain for the design life of the project, under designated load application. In the field application, the polymer dilution is sprayed normally into the loose soil. After polymer dilution penetrates into the soil, compaction of the "wet" soil is carried out. The stabilized soil gains strength after water evaporates from its soil mix. Traditional stabilization of soil relies on cement, lime, fly ash, and bituminous [1-3] material. As the scientists and researchers are developing new engineering materials, many non-traditional materials are available for soil stabilization, for examples polymer emulsion, acids, enzymes and tree resin emulsions [4-7]. As compared to the traditional stabilizers, these stabilizers have the following advantages:

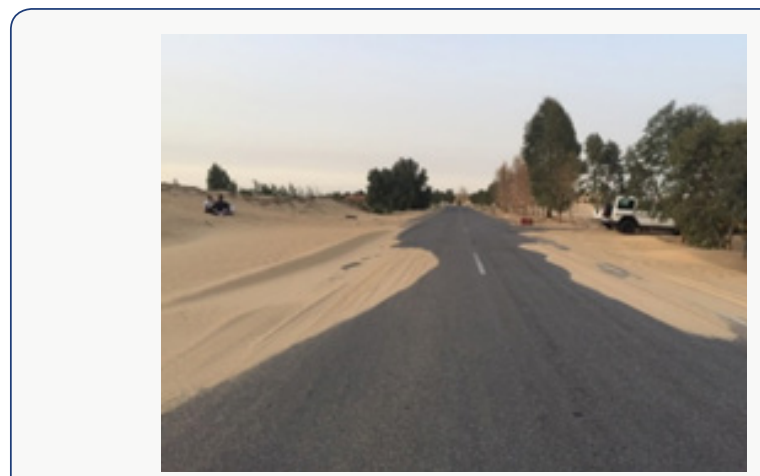

Figure 1: Road covered by sand. 
a) Stable chemical properties;

b) They produce less swelling and heaving $[8,9]$;

c) Produce less pollution; and

d) They save natural resources.

Apart from above mentioned benefits another advantage is that the liquid concentrate can be diluted with water and thus it is easy to achieve target additive amount by controlling dilution ratio. In many countries, large percentages of roads and parking lots are unpaved. The vehicles and wind together with the loose soil create dust that are known for adverse environmental and human health impact. Apart from increasing the strength of the soil these stabilizers can also be used as a way for controlling dust. For the ease of transportation and storage these Polymer emulsions can also be prepared in the form of powder. Before field application it is important for the industries to understand the mechanical properties of stabilized soil primarily during development phase of the product. Thus, the main objective of this paper is to highlight a quick and easy way to evaluate the mechanical performance of such stabilized soil before actual field application. Such assessment will quickly provide them a guide to modify their product if at all needed. For a comparison study, three in development products from the same company namely a) L13126; b) L13140; c) L13142 and one a market ready "Product A" is chosen, all as anonymous reference products. Overall, they constitute three polymer emulsions and one polymer powder type as described later in the paper. Goals within the scope of this paper include the following:

a) In detail description of sample preparation

b) To evaluate the property and suitability of the sandy soil before the addition of stabilizer developed by chemical polymerization techniques

c) To evaluate the property and suitability of the sandy soil after the addition of the stabilizer

d) To investigate the influence of the mechanical properties of the sandy soil with the polymer emulsion (in terms of mix proportion, percentage of stabilizing additive, water content and permeability of the stabilized soil matrix)

e) To demonstrate the influence of the emulsion types, curing time and wetting condition on the mechanical response of the stabilized soils

f) At last, present a relative ranking of various soil stabilizer products

The outcome of the tests is analyzed in terms of unconfined compressive (UC) tests. It is hereby noted that other tests such as California Bearing Ratio (CBR) [10,11], triaxial (confined and unconfined), resilient modulus, and cyclic wet dry tests are also valid tests to investigate the performance of the stabilized soils. However, for a rapid screening of stabilizers, the UC test was preferred. In this investigation, the compacted stabilized sandy soil samples were 'cured' under controlled temperature and humidity conditions before the soaked and un soaked unconfined compressive strength (UCS) tests were performed.

\section{Material and Method}

\section{Materials Used}

Four different kinds of stabilizers were used in this study, three polymer emulsion type namely: L13126, L13142 and Product A and one powder polymer type namely: L13140. Table 1 lists the polymer type and solid content of individual emulsion type, which was obtained by drying a known weight of emulsion in the oven at $105^{\circ} \mathrm{C}$ to a fixed weight. The sandy soil samples which contain $10 \%$ china clay and $90 \%$ sand were considered which more or less represent a dust prone unpaved soil road. The sand used in this research is natural sand in Netherland, the gradation is showed in Figure 2.

Table 1: Polymer stabilizer type and polymer solid content.

\begin{tabular}{|c|c|c|}
\hline Polymer Emulsion & Type of Polymer & Solid Content (\%) \\
\hline L13126 & Styrene-acrylates & 50 \\
\hline L13140 & $\begin{array}{c}\text { Poly-vinyl acetate- } \\
\text { Copolymer }\end{array}$ & 100 \\
\hline L13142 & $\begin{array}{c}\text { Poly-vinyl acetate- } \\
\text { Copolymer }\end{array}$ & 54.7 \\
\hline Product A & $\begin{array}{c}\text { Poly-vinyl acrylate- } \\
\text { Copolymer }\end{array}$ \\
\hline
\end{tabular}

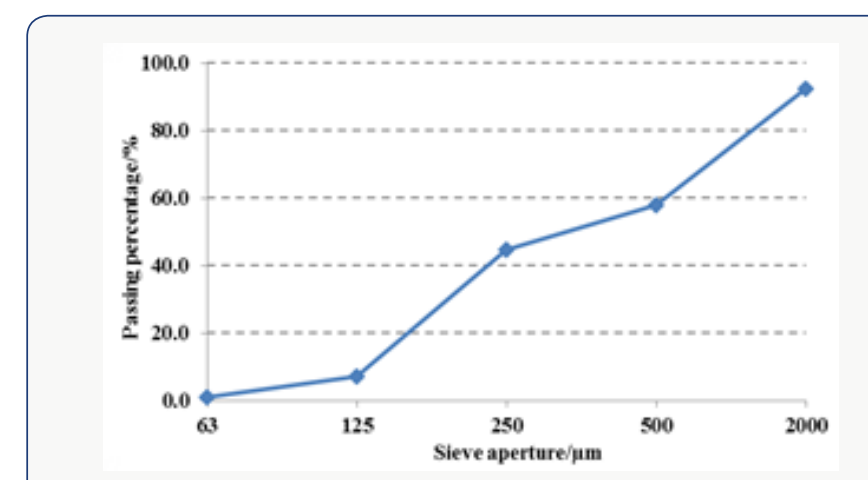

Figure 2: Sieving test result of natural sand.

\section{Specimens Preparation}

In order to perform compression tests, cylindrical specimens of $100 \mathrm{~mm}$ diameter and $150 \mathrm{~mm}$ height were prepared. The optimum moisture content of the sandy soil without stabilizer was measured by the modified proctor method (ASTM D1557). Figure 3 shows the result of modified proctor test. From the plot of the Figure 3, it can be observed that the optimum moisture content of this sandy soil is about $10.3 \%$. With the known optimum moisture content and the known maximum dry density of the sandy soil, gyratory compactor was utilized (at $600 \mathrm{k}_{\mathrm{Pa}}$ vertical stress, 30 gyrations/ 
min and $1.25^{\circ}$ tilt angle) for the preparation of specimens. In order to mix the polymer stabilizer and soil uniformly, the stabilizer concentrate was diluted in the water before putting it into the sandy soil mixture. The dilution ratio was based upon the optimum moisture content and the amount of stabilizer used. For providing enough space for the polymer concentrate in the soil matrix, the stabilizer amount and the amount of water to be added is calculated on the basis of the optimum moisture content i.e. $10.3 \%$. The actual density of polymer emulsion was assumed to be $1 \mathrm{Kg} / \mathrm{L}$. The preparation of sample was carried out in following six steps: soil preparation, additive preparation, soil-additive mixing, moulding, compaction, curing. The soil was mixed for five minutes before the addition of dilution. The amounts of added stabilizer were $14 \mathrm{~L} / \mathrm{m}^{3}$ (i.e. $1 \mathrm{~m}^{3}$ compacted soil contains 14L stabilizer concentrate), 19L/ $\mathrm{m}^{3}$ and $24 \mathrm{~L} / \mathrm{m}^{3}$ respectively. The dilution ratio was calculated by the following equation:

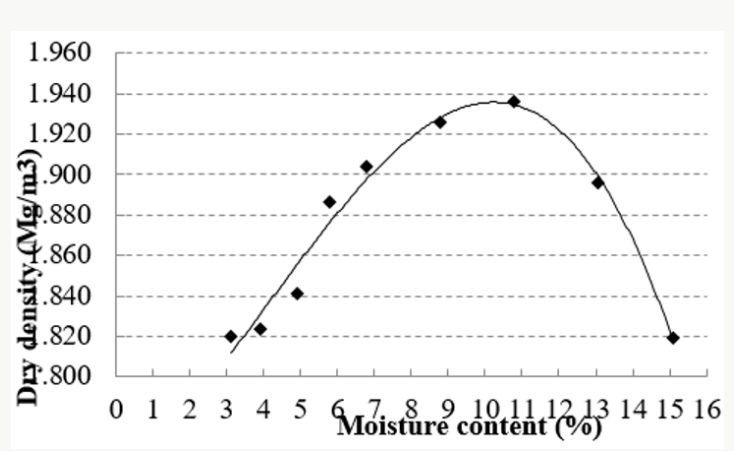

Figure 3: Modified proctor test result.

where: R: dilution ratio

$\mathrm{x}$ : optimum water content $(\%)$

y: maximum dry density of soil $\left(\mathrm{Mg} / \mathrm{m}^{3}\right)$

z: amount of adding polymer $\left(\mathrm{L} / \mathrm{m}^{3}\right)$

$\rho$ : the density of stabilizer in the test temperature $(\mathrm{Mg} / \mathrm{L})$

Assuming the depth of penetration in pavement to be $15 \mathrm{~cm}$, the amount of addition of stabilizer i.e. $14 \mathrm{~L} / \mathrm{m}^{3}, 19 \mathrm{~L} / \mathrm{m}^{3}, 24 \mathrm{~L} / \mathrm{m}^{3}$ is equivalent to $2.1 \mathrm{~L} / \mathrm{m}^{2}, 2.85 \mathrm{~L} / \mathrm{m}^{2}, 3.6 \mathrm{~L} / \mathrm{m}^{2}$ respectively. After the soil and additive preparation steps, the dilution was mixed with sandy soil by using rotary mixer, until a uniform mixture was achieved. The specimen was prepared by using a gyratory compactor mould of $102 \mathrm{~mm}$ diameter and $254 \mathrm{~mm}$ height. The material was placed in three layers in the mold and each layer was compacted with rod for 25 times in order to get a uniform specimen. After molding step, the sample was placed in the gyratory device and compacted until the height of the sample was reduced to $150 \mathrm{~mm}$. The compacted sample was then extruded from the gyratory mould by the hydraulic jack extrusion device mounted on the gyratory machine. The compacted sample was then placed in the curing room at $200 \mathrm{C}$ and 40 percent relative humidity. In order to simulate the field condition, air-dried curing process was used. Each sample was weighed after 3 days, 7 days, 14 days, 21 days, and 28 days to get the moisture loss rate.

\section{Unconfined Compression Test}

The sandy soil samples stabilized with the different type and number of additives were tested by using unconfined compression (UC) setup under soaked and un soaked conditions. In the soaked UC test, the dry sample was placed in the $25 \mathrm{~mm}$ deep water bath for 15 minutes and after removing it from the water it was drained for 5 minutes. Then the soaked samples, as shown in Figure 4, were tested. The soaked UC test reflects the influence of moisture on the strength reduction of the stabilized soil in the field condition.

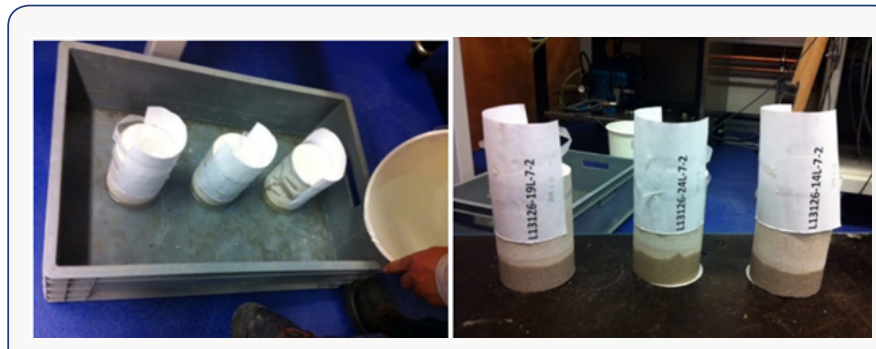

Figure 4: Samples soaked in the water bath.

\section{Permeability Test}

Permeability test was conducted to evaluate the capability of the stabilized soil samples to allow the water pass through it. The falling water head setup, see, is used for measuring permeability of the sandy soil samples with different types and amounts of the additives. In this test a sample is connected to a standpipe which provides both the water head and the means of measuring the quantity of water flowing through the sample. The permeability value is calculating by using the following formula:

Where: Kt: permeability(m/s)

a: cross section area of used manometer tube $\left(\mathrm{cm}^{2}\right)$

A: cross section area of sample in permeameter cell $\left(\mathrm{cm}^{2}\right)$

t: measured time interval (s)

L: length of sample $(\mathrm{cm})$

$\mathrm{h}_{1}$ : start level manometer tube distance above overflow level (cm)

$h_{2}$ : end level manometer tube distance above overflow level $(\mathrm{cm})$

The parameters a, A, L were calculated on the basis of geometry of the samples and the manometer tube. The test was carried out after the sample was fully saturated. After that, the water tube is filled to a prescribed starting level $\mathrm{h}_{1}$. After $\mathrm{t}$ seconds, the water 
head level $h_{2}$ in the manometer tube is recorded. By using the equation mentioned above the permeability $\mathrm{K}_{\mathrm{t}}$ is calculated. The procedure is repeated at least three times interval until the $\mathrm{K}_{\mathrm{t}}$ value is constant.

\section{Results and Discussion}

\section{Optimal Polymer Adding Amount}

Preliminary test was conducted to get a reasonable amount of stabilizer quantity to be investigated, L13126 polymer was taken as an example, various additive amounts of $0 \mathrm{~L} / \mathrm{m}^{3}$ (pure water), $1.5 \mathrm{~L} /$ $\mathrm{m}^{3}, 7 \mathrm{~L} / \mathrm{m}^{3}, 14 \mathrm{~L} / \mathrm{m}^{3}, 19 \mathrm{~L} / \mathrm{m}^{3}$ and $24 \mathrm{~L} / \mathrm{m}^{3}$ stabilizer quantity were examined. Figure 5 shows a plot of the additive amount versus UCS results after 28 days curing. As shown in Figure 5, the compression strength increases with stabilizer adding amount, it is expected that higher polymer content leads to thicker polymer matrix and more interaction between the soil particles, the compression strength increase almost linearly. It is hereby defined that "incremental strength" means the UCS of stabilized sample deducted by the UCS of samples with pure water. According to the Netherlands specification, the minimum UCS of bounded base layer shall be not less than 2MPa. Therefore, in this investigation, the incremental UCS value of $2 \mathrm{MPa}$ was set as our minimum strength requirement. As can be seen from the prediction curve of Figure 5, the stabilized soil with $19 \mathrm{~L} / \mathrm{m}^{3}$ additive amount can reach $2 \mathrm{MPa}$. Therefore, the additive amount around $19 \mathrm{~L} / \mathrm{m}^{3}$ i.e. $14 \mathrm{~L} / \mathrm{m}^{3}$ and $24 \mathrm{~L} / \mathrm{m}^{3}$ and at $19 \mathrm{~L} / \mathrm{m}^{3}$ were investigated in the new test plan for all the polymer stabilizers.

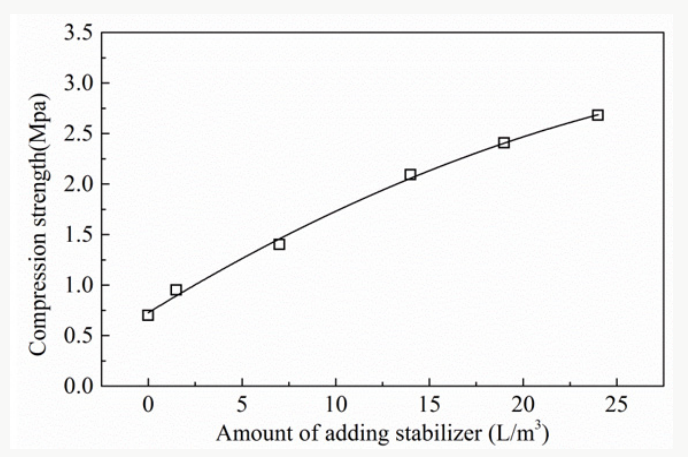

Figure 5: Preliminary UCS test results.

\section{Polymer Adding Amount Effect}

Figure 6 presents the UCS of sandy soil sample stabilized with different type and different adding amount after 28 days curing period. All the stabilized sandy soil demonstrated remarkable increase in UCS than the sample mixed with only pure water. The highest UCS value after 28 days curing period was found for Product A stabilized sandy soil which was higher than the sample stabilized by L13126. The L13140 and L13142 stabilized sandy soil show almost similar UCS values. However, as compared to the L13126 and Product A, these two stabilizers display lower UCS values. It is also noted hereby that UCS value increased with the increase in the stabilizer adding amount.

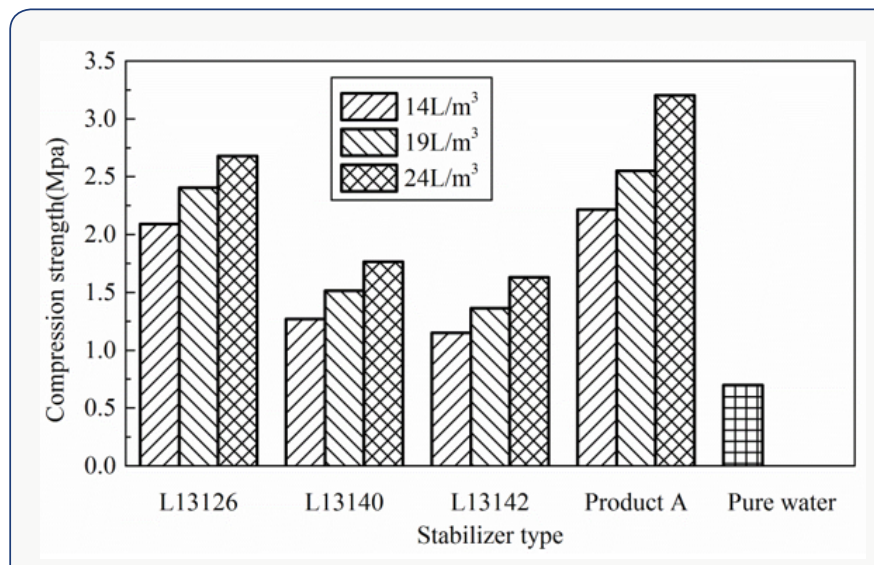

Figure 6: UCS values after 28 days curing.

\section{Wet and Dry Condition Effect}

The soaked UCS of the sandy soil samples with pure water were not able to be tested because the samples disaggregated in the water bath. For comparison of moisture sensitivity of the samples, the strength loss rate of different stabilized samples was determined as Figure 7 In general, it can be observed that the strength loss rate decreases with the increase in the stabilizers amount, it indicates the thicker polymer coating will prevent moisture diffusion better. L13140 powder polymer specimens provide better water resistance to moisture deterioration and lose about $20 \%$ compression strength, the compression strength loss rate of others stabilizer specimens is about $30 \%$. The specimens without stabilizer begin to disintegrate when they are placed in the water, and then lose load bearing capacity, the polymer can improve the water resistance of sandy soil.

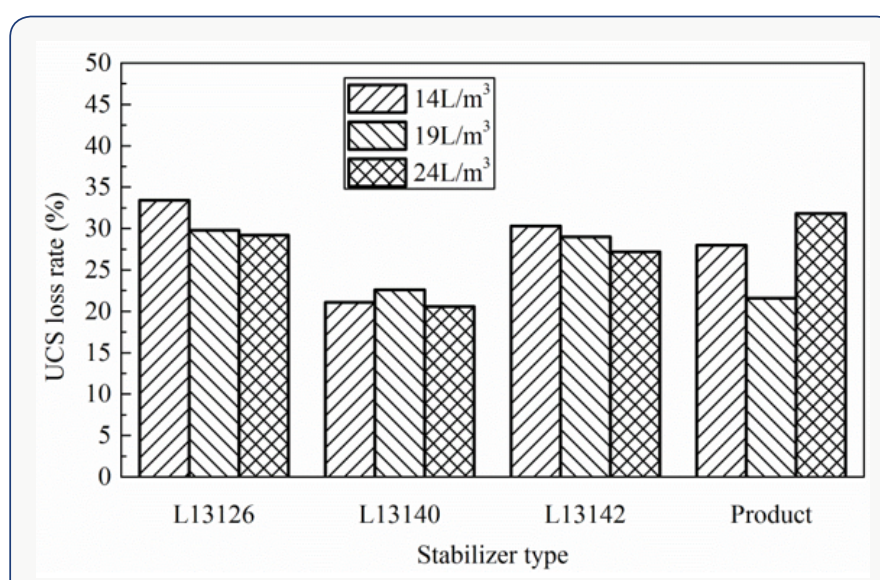

Figure 7: UCS soaked loss rate after 28 curing days.

\section{Curing Time and moisture lose effect}

The effect of curing time on residual moisture rate is presented in Table 2, the value is based on the original water adding weight and the water loss weight. The samples were weighted after $3,7,14$, 
21 and 28 curing days, as shown in Table 2, the residual moisture rate became a constant, almost all the moisture has evaporated by the 14th day of curing for all the stabilizer specimens with different adding amount, the final value is not zero duo to the moisture loss in the mixture process. Comparing the values of specimens with stabilizer and pure water, the different is slight, it illustrates polymer do not affect the moisture evaporation. The moisture evaporates from the sample that will enhance the bonding between polymer and soil particles, the relation between compression strength and residual moisture rate are shown in Figure 8, duo to residual moisture rate decrease with curing time for all the specimens is similar, for brevity, the residual moisture rate result of pure water sample is taken as an example to compare with the compression strength variation. The sample with polymer stabilizers develop approximately $60 \%$ of the 28 days compression strength within the first 7 days of curing, however, the strength growth after 14 days curing period is not significant, the strength growth trend is similar to that of residual moisture rate decrease, this indicates that the gain in strength of the stabilized sample may only be related to the rate of moisture evaporation and not to any chemical reaction as normally observed in cementitious stabilized products.

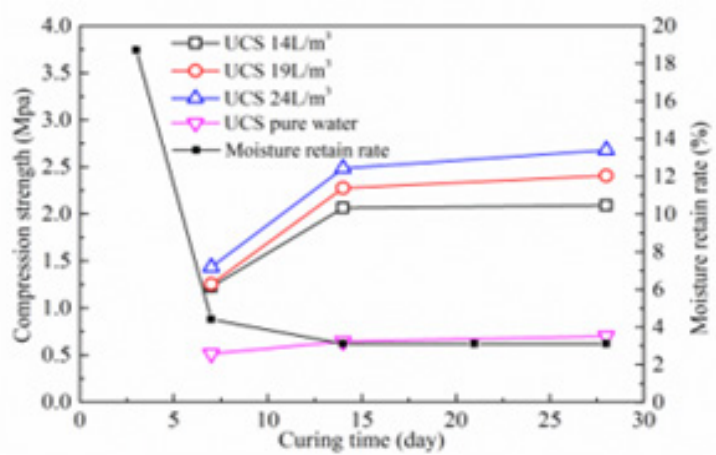

(a) L13126

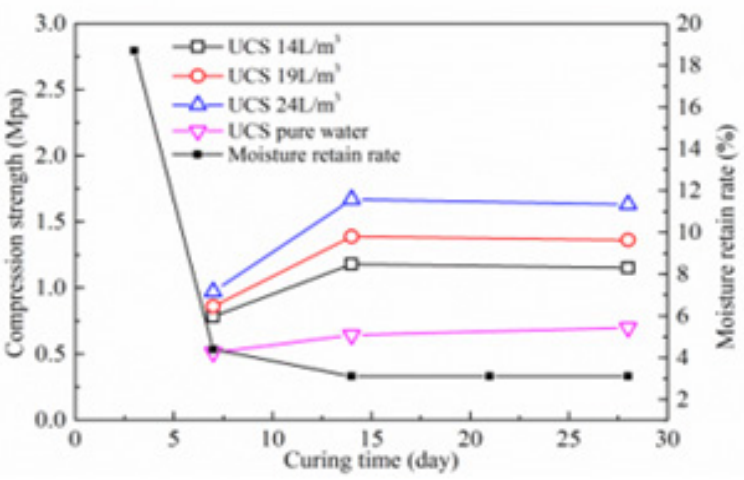

(c) L13142

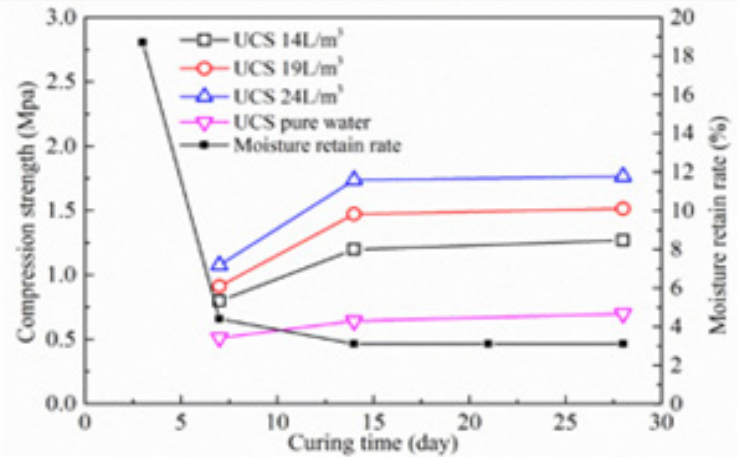

(b) $\mathrm{L} 13140$

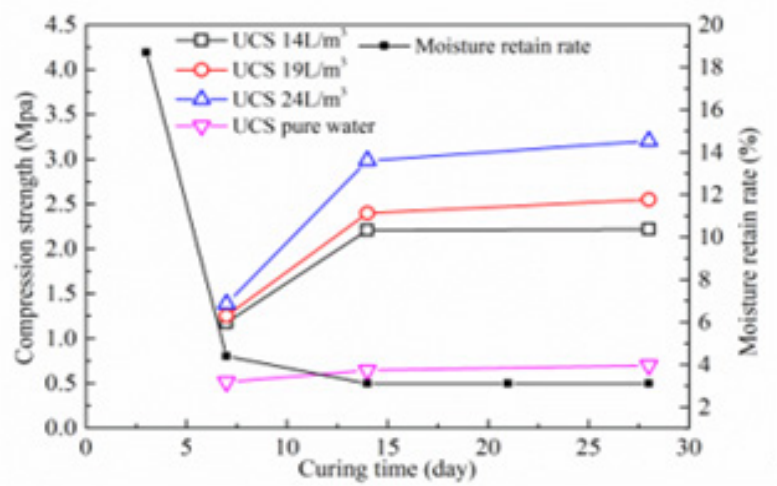

(d) Product A

Figure 8: Effect of curing time on compression strength.

Table 2: Residual moisture rate.

\begin{tabular}{|c|c|c|c|c|c|c|}
\hline \multirow{2}{*}{ Stabilizer Type } & \multirow{2}{*}{ Adding Amount $\left(\mathrm{L} / \mathrm{m}^{3}\right)$} & \multicolumn{5}{|c|}{ Residual Moisture Rate (\%) } \\
\hline & & 3 Days & 7 Days & 14 Days & 21 Days & 28 Days \\
\hline \multirow{3}{*}{ L13126 } & 14 & 15.6 & 5.1 & 3.3 & 3.3 & 3.3 \\
\hline & 19 & 19.9 & 5.7 & 3.2 & 3.2 & 3.2 \\
\hline & 24 & 18.2 & 5.5 & 2.7 & 2.7 & 2.7 \\
\hline \multirow{3}{*}{ L13140 } & 14 & 22.6 & 5.8 & 3.3 & 3.3 & 3.3 \\
\hline & 19 & 19.4 & 6.1 & 3.2 & 3.2 & 3.2 \\
\hline & 24 & 20.9 & 6.2 & 3.2 & 3.2 & 3.2 \\
\hline
\end{tabular}




\begin{tabular}{|c|c|c|c|c|c|c|}
\hline \multirow{3}{*}{ L13142 } & 14 & 18.2 & 5.6 & 3.5 & 3.5 & 3.5 \\
\cline { 2 - 7 } & 19 & 20.6 & 5.6 & 2.9 & 2.9 & 2.9 \\
\cline { 2 - 7 } & 24 & 19.1 & 5.4 & 2.5 & 2.4 & 2.4 \\
\hline \multirow{3}{*}{ Product A } & 14 & 19.2 & 6.1 & 3.1 & 3.1 & 3.1 \\
\cline { 2 - 7 } & 19 & 20.5 & 5.9 & 2.3 & 2.3 & 1.9 \\
\cline { 2 - 7 } & 24 & 18.5 & 5.7 & 2 & 3.9 & 3.1 \\
\hline
\end{tabular}

The moisture in the stabilized sample will influence the soaked UCS loss rate, the effect of curing time on USC loss rate is shown in Figure 9. In general, the USC loss rate decrease with the increase of curing time, the trend is similar to that of strength growth, it illustrates the sample with less moisture inside has a better moisture damage resistance. Samples utilized for permeability test were prepared in the same method as the ones used in the UC test (refer to "Specimens preparation" section). As shown in Figure 10, sample is kept inside the tube with no side flow allowed and the bottom $2 \mathrm{~cm}$ of the sample is utilized to apply silicon glue. After filling up the tube with water the test equipment is left for one day to be able to fully saturate the sample. The permeability test was carried out on the samples stabilized by L13126, L13140, L13142 and Product A with $19 \mathrm{~L} / \mathrm{m}^{3}$ additive amount, 3 replicates for each case, the permeability results are presented in the Table 3. It can be observed that all the sandy soil samples stabilized by the polymer stabilizers show lower permeability which is important for pavement surface layer to prevent rain water infiltration into the deeper part of the road foundation, soil stabilized by L13142 show highest permeability.

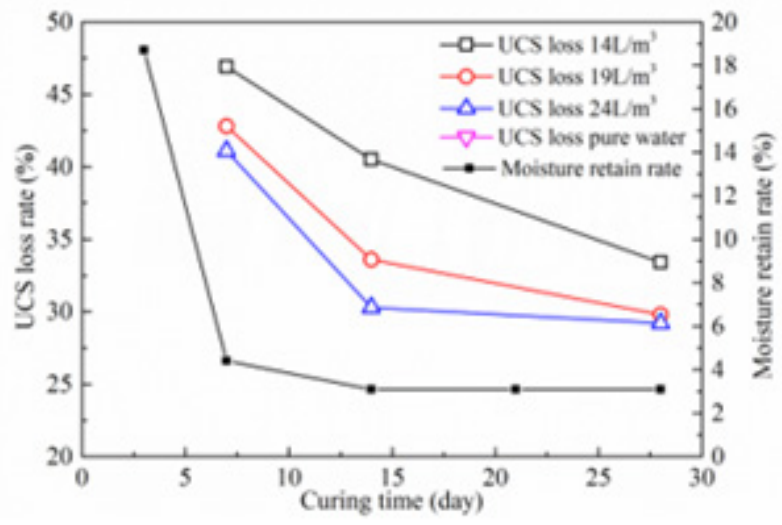

(a) L13126

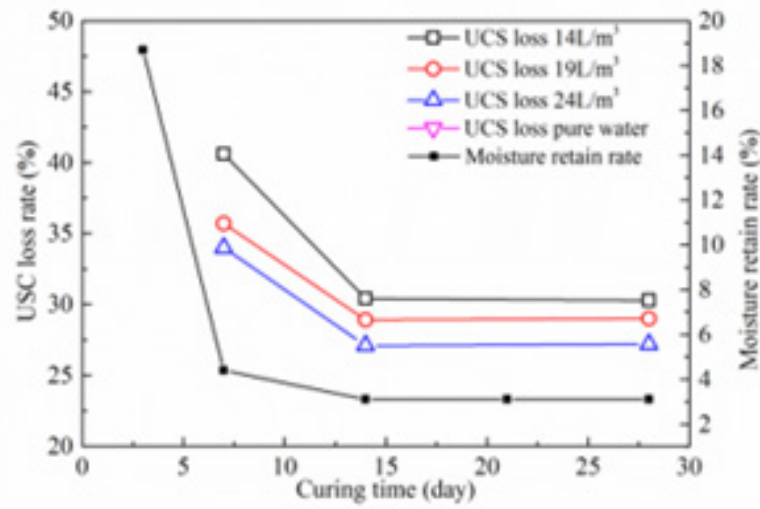

(c) L13142

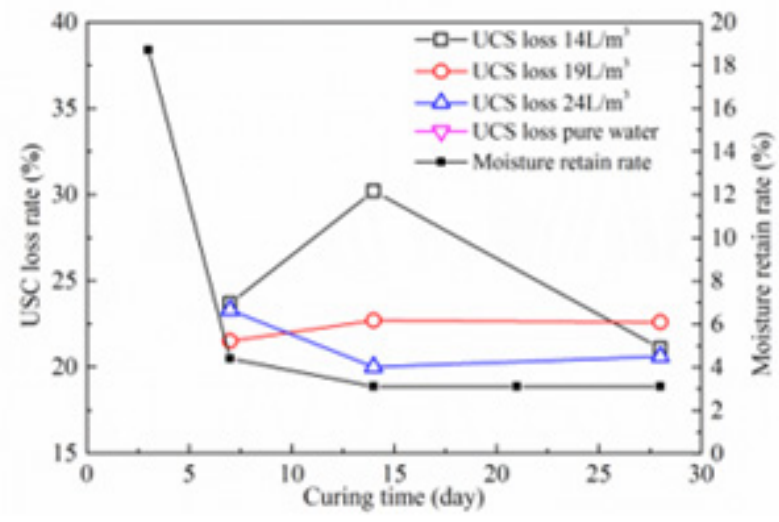

(b) L13140

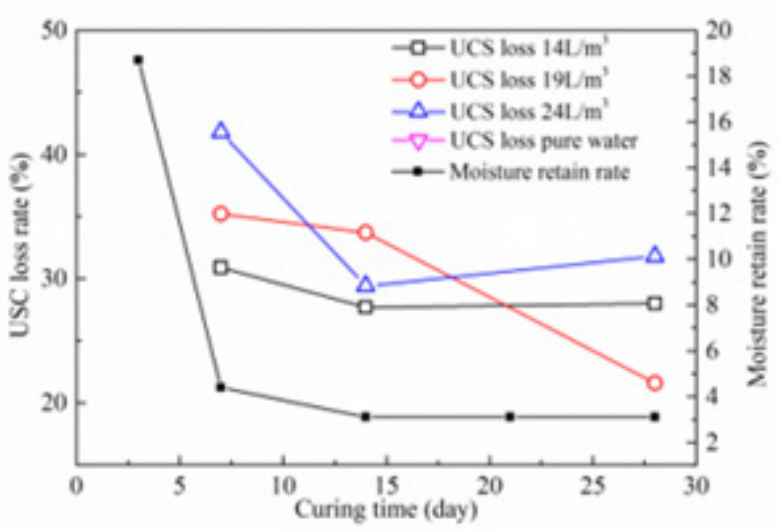

(d) Product $\mathrm{A}$

Figure 9: Effect of curing time on USC loss rate. 


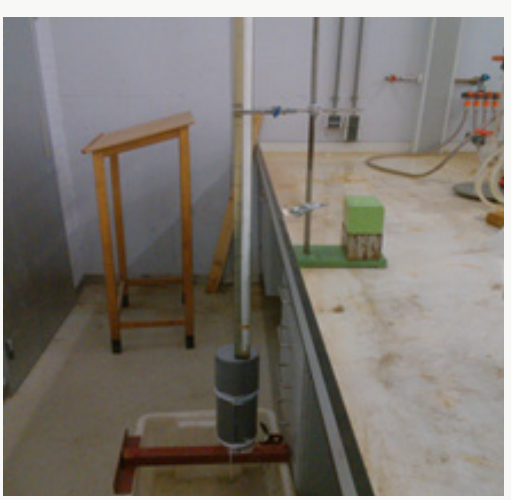

Figure 10: Permeability test equipment.

Table 3: Permeability test results.

\begin{tabular}{|c|c|c|c|c|}
\hline \multirow{2}{*}{$\begin{array}{c}\text { Stabilizer } \\
\text { Type }\end{array}$} & \multicolumn{4}{|c|}{$\mathbf{K}_{\mathbf{t}}\left(\mathbf{1 0}^{-\mathbf{7}} \mathbf{~} / \mathbf{s}\right)$} \\
\cline { 2 - 5 } & $\mathbf{1}$ & $\mathbf{2}$ & $\mathbf{3}$ & Average \\
\hline L13126 & 5.31 & 5.50 & 5.50 & 5.44 \\
\hline L13140 & 6.70 & 6.27 & 6.90 & 6.62 \\
\hline L13142 & 3.13 & 2.82 & 2.63 & 2.86 \\
\hline Product A & 4.84 & 4.87 & 4.96 & 4.89 \\
\hline
\end{tabular}

\section{Implication and Discussion}

Polymer is an environmental way for dust control and soil stabilization, as important as dust control, the mechanical and hydraulic property are also key points of polymer application, in this paper, mechanical and hydraulic property include three key indexes: UCS, soaked UCS loss rate and permeability, after 28 curing days, the moisture evaporate from the stabilized soil, the specimens become stronger and have a lower UCS loss rate. Unfortunately, there are no significant relation between the three indexes for all the polymers, the highest UCS is product A, the lowest UCS loss rate is L13140, and the lowest permeability is L13142, therefore it is hard to find a polymer with higher UCS, lower UCS loss rate and lower permeability, for the application, field condition, strength requirement and cost should be considered for stabilizer selection.

\section{Conclusion}

This paper in detail describes a quick and easy way, from sample preparation stage to experimental tests, to evaluate the performances of four kinds of stabilizers on sandy soil. With the results obtained from the tests one can examine the relative performances of various stabilizers. Such tests can be performed during product development phase itself. For example, from all the samples examined, tests results indicated that soil stabilized by L13126 has higher UCS both in soaked and un soaked conditions than the one stabilized by L13140 and L13142 and it is comparable to market ready Product A. The 28 days UCS of sandy soil samples stabilized by using 19L/m3 of L13126 and Product A can reach to a desired value of $2 \mathrm{Mpa}$ (as per recommendation). Sandy soil stabilized by polymer powder L13140 is slightly stronger than the one stabilized by the polymer emulsion L13142. Such information can be used in the ranking of various products. Other findings that can be drawn from the results presented in this paper are summarized as follows.

a) This study shows that the strength of the stabilized sandy soil is significantly increased both under wet and dry conditions by using the polymer additives.

b) The UCS values of the sandy soil samples demonstrate that the polymer-stabilized soil properties improve with the curing conditions and the additive amount.

c) The increase in strength is observed due to the deposition of the solidified polymer components after water evaporates from the emulsion. The amount of polymer deposited on the surface of the soil particle depends on the concentration of the polymer and to the degree of mixing.

d) The compressive strength growth rate of the stabilized soil correlates with the moisture loss rate in the sample. There is no further strength increase when sample completely loses its moisture.

e) After 14 days, most stabilized soil samples reach the maximum compressive strength.

f) As compared to the cement \& lime stabilized soil in literature, the stabilized soil sample shows higher deformability.

g) Sandy soil sample stabilized by the polymer stabilizers show lower permeability.

\section{Acknowledgment}

This work is the research study of TU Delft. The authors would like to thank the research staff of road engineering, special thanks to Wim Ver waal from Geotechnical group of TU Delft to design an appropriate test setup for the sandy soil permeability measurement.

\section{References}

1. Meyers JF, R Pichumani, BS Kapples (1976) Fly Ash as a Construction Material for Highways: A Manual. FHWA, USA Report No: FHWAIP-76-16.

2. (1990) State-of-the-Art Report on Soil Cement. ACI Materials Journal, American Concrete Institute, Farmington Hills Mich, USA 87(4): 395417.

3. Prusinski JR, S Bhattacharja (1999) Effectiveness of Portland cement and lime in stabilizing clay soils. In Transportation Research Record: Journal of the Transportation Research Board, Washington, DC, USA 1652: 215-227.

4. Tingle JS, RL Santoni (2003) Stabilization of clay soils with nontraditional additives. In Transportation Research Record: Journal of the Transportation Research Board Washington, DC, USA 1819: 72-84.

5. Santoni RL, JS Tingle, SL Webster (2002) Stabilization of silty sand with nontraditional additives. In Transportation Research Record: Journal of the Transportation Research Board Washington, DC, USA 1787: 61-70. 
6. Newman JK, Tingle JS, Gill C (2005) Stabilization of silty sand using polymer emulsions [J]. International Journal of Pavements 4(1-2): 1-12.

7. Newman K, Rushing JF (2005) Stabilization of silty sand using combination of hydraulic cements and polymer emulsions. Presented at $84^{\text {th }}$ Annual Meeting of the Transportation Research Board, Washington, DC, USA.

8. Mitchell JK (1986) Practical Problems from Surprising Soil Behavior. Journal of Geotechnical Engineering, ASCE, 112(3): 259-289.

9. Kota PBVS, D Hazlett, L Perrin (1996) Sulfate-Bearing Soils: Problems with Calcium-Based Stabilizers. In Transportation Research Record:
Journal of the Transportation Research Board, Washington, DC, USA 1546(1): 62-69.

10. Ajayi Majebi A, WA Grissom, LS Smith, EE Jones (1991) Epoxy-ResinBased Chemical Stabilization of a Fine, Poorly Graded Soil System. In Transportation Research Record: Journal of the Transportation Research Board,Washington, DC, USA 1295: 95-108.

11. Lucian C (2012) Stress-Strain Behaviours Of Two Stage Lime-Cement Treated Expansive Soils. International Journal of Modern Engineering Research 2(6): 4405-4409.

\section{(c) (i) \\ This work is licensed under Creative Commons Attribution 4.0 License}

To Submit Your Article Click Here:

Submit Article

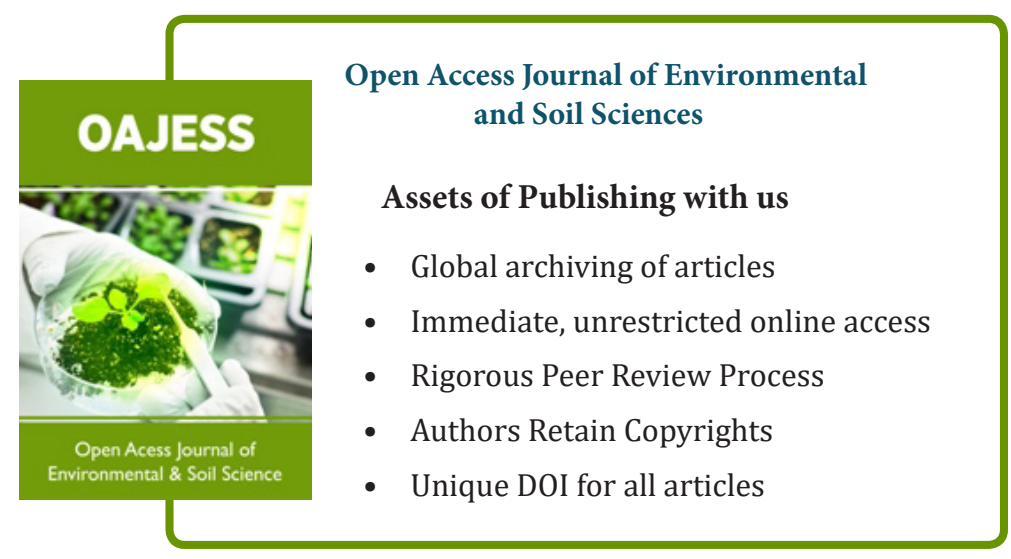

